\title{
Interaction of Brilliant Blue dye solution with soil and its effect on mobility of compounds around the zones of preferenial flows at spruce stand
}

\author{
Juraj Bebej ${ }^{1 *}$, Marián Homolákํㅜ Tomáš Orfánus² \\ ${ }^{1}$ Technical University in Zvolen, Faculty of Forestry, T. G. Masaryka 24, SK-960 53 Zvolen, Slovak Republic \\ ${ }^{2}$ Institute of Hydrology SAS, Račianska 75, SK - 83102 Bratislava, Slovak Republic
}

\section{Abstract}

We performed field experiment with $10 \mathrm{~g} \mathrm{l}^{-1}$ concentration of Brilliant Blue solutes in $100 \mathrm{l}$ of water sprinkling on 1 $\times 1 \mathrm{~m}$ surface of the Dystric Cambisol. Consequently, four vertical profiles were exposed at experimental plot after 2 hours (CUT 2), 24 hours (CUT 24), 27 hours (CUT 27) and after 504 hours (CUT 504) in order to analyse spatiotemporal interactions among the BB solution (Na-salts), soil exchangeable complex and fine earth soil (\%) samples extracted from both the high and low coloured zones located around the optically visualised macropore preferred flow (PF) zones. The concentration changes were quantifying via soil profiles not affected by BB (termed as REF) located in the close vicinity of experimental plot. Observed changes in $\mathrm{pH}\left(\mathrm{H}_{2} \mathrm{O}\right)$, chemical composition of fineearth soil, as well as in concentration of $\mathrm{Na}^{+}$in soil exchangeable complex to suggest, the BB dye solution didn't represent an inert tracer, but compounds strongly involved in reaction with surrounding soils. Recorded chemical trends seems to be the result both the competitive processes between the $\mathrm{Na}^{+}$of $\mathrm{BB}$ dye solution and composition of surrounding soil exchangeable complex, as well and the spatial-temporal controlled mechanism of dye solution transfer in soil.
\end{abstract}

Key words: preferential flow; compounds migration; spatial-temporal evolution; dye solution- soil interaction; Brilliant Blue dye

Editor: Pavel Pavlenda

\section{Introduction}

Bundt et al. (2001a, b) were probably the first to investigated whether preferential flow path $(\mathrm{PF})$ have higher microbial biomass and different microbial community structures than the rest of soil at a forested site. Bogner et al. (2012) showed the different $\mathrm{pH}$ values, concentrations of $\mathrm{C}, \mathrm{N}, \mathrm{Fe}, \mathrm{Ca}$ and $\mathrm{Mg}$ in zones of preferential flow in comparison with rest of soils. The cited authors used Brilliant Blue (BB) dye solution to visualisation of macropore preferential flow path and its research was based on assumption the stained areas of preferential flow paths remain stable down to subsoil (Ritsema \& Dekker, 2000) and the BB represents an inert compound not involved into the dye solution-surrounding soil interaction.

On the other hand, Flury \& Flühler (1994) noted the BB dye represents $\mathrm{Na}$-salts much more susceptible to sorption processes in soil when compared to anionic forms of the dye and in consequence, its complex reactions with surrounding, soil can alter soil sorption characteristics leading to risk of fatal misinterpretations by studying chemical processes in soil while using dye solution (Flury \& Wai 2003). The properties of BB as Na salts in field condition have not been explored till now, and only the results of laboratory batch sorption studies are available to show, the adsorption of BB on soil particles can be described by the Freundlich isotherm if the dye concentration is low $0.1-15 \mathrm{mg} \mathrm{l}^{-1}$ (Flury \& Flühler 1995; Perillo et al. 1998), or by the Langmuire isotherm by concentrations $100-5000 \mathrm{mg} \mathrm{l}^{-1}$ (Ketelsen MeyerWindel 1999). Some breaktroughts of these experiments to show relationships among the dye sorption, the $\mathrm{pH}$, the clay content as well as the composition of secondary minerals in soils (Germán-Heins \& Flury 2000).

The role on sodium as component of Brilliant Blue FCF (BB) (5.8\% of the BB molecule weight) may have essential effect not only on movement and redistribution of chemical elements around the PF paths (Sparks 2003), but also on modification of soil structure and resulting water transport processes on the boundaries between the gravitational pores and the soil matrix themselves (Brady \& Weil 2001). 
The information about spatial-temporal controlled process of dye solution movement around the zones of macroscopically visible PF pathways in soils are missing till now, due to the disadvantage of staining experiments during the soil sampling: excavation of pedon is destructive and experimental results cannot be repeated at the same location (Flury et al. 1994), hence the sampling is limited usually per sole vertical dye pattern of soil profile exposed on experimental plot usually 12 or 24 hours after the dye application (Flurry \& Flühler 1994; Flurry et al. 1994; Hagedorn \& Bundt 2002; Bogner et al. 2012; Bundt et al. 2001; Garrido et al. 2014). On the other hand, the movement of water in soil around the zones of PFs can be extremely dynamic process, different types of PFs: macropore flow, finger flow (Ritsema \& Dekker 1995) and funnelled (or heterogeneous) flow (e.g. Kung 1990; Roth 1995) may occur individually, in tandem (Jury \& Horton 2004), or over time they can convert to s matrix flow (Jarvis \& Dubus 2006).

In order to evaluate the concept of spatial-temporal controlled movement of dye solution in soils, as well as to screening the role of sodium during the BB dye solution movement in soils around the zones of PF, we designed the field experiment based on next working hypothesis:

- the object of study on experimental plot - a soil pedon-represents spatially homogenous body, with identical stratification of soil horizons, identical soil textures, the same chemical and mineralogical composition of fine earth soil and volumetric content of soil skeleton,

- macropore PF pathways visualised by BB dye solution in particular soil profiles (CUTs), exposed on experimental plot in different time will represents $2 \mathrm{D}$ cross sections of different $\mathrm{PF}$ pathways, but with common history of dye solution movement,

- the observed chemical changes in dye pattern profiles exposed in different time are to be the consequences of dye solution movement and its interaction with surrounding soils,

- the soil profiles labelled as reference (REFs) non affected by dye solution irrigation experiment and excavated in close vicinity of experimental plot, with identical stratification of soil horizons, soil textures, chemical, mineralogical composition and volumetric content of soil skeleton as recorded on the experimental plot, will enable to quantify the effects of chemical changes observed.

The objective of proposed article is:

(I.) to analyse and to quantify the chemical changes in composition of fine earth soils sampled of soil profiles exposed in different time induced by Na salt BB dye solution movement in soil pedon after irrigation experiment within the spatial-temporal framework,
(II.) To analyse and to quantify the spatial-temporal chemical changes in concentration of $\mathrm{Na}^{+}$in soil exchangeable complex and corresponding changes at $\mathrm{pH}\left(\mathrm{H}_{2} \mathrm{O}\right)$ induced by application of $\mathrm{Na}$ salt $\mathrm{BB}$ dye solution,

(III.) To evaluate the consequences of finding obtained regarding the concept of spatial-temporal controlled movement of dye solution in soils proposed.

\section{Material and methods}

\subsection{Description of the experimental site}

The research was performed at Panský diel (N 48 48' 25,76", E 1909'20,47"') in Slovakia at altitude of $910 \mathrm{~m}$ above sea level, covered by a 90-year old mixed forest of Norway spruce (Picea abies [L.] Karst.), as a dominant species, silver fir (Abies alba Mill.), and European beech (Fagus sylvatica L.), Weymouth pine (Pinus strobus L.) and European larch (Larix decidua Mill), where the climate vary from moderately warm, humid to moderately cold with mean annual temperature of $4.1^{\circ} \mathrm{C}$, and where the mean annual precipitation is $1,023 \mathrm{~mm}$.

The experimental site was located on a flat area with negligible inclination, and its geology contained complexes of sediments formed from schist, acidic granitites, arkoses, greenish and reddish mica-slates and quartzite (Andrusov et al.1985). These rocks were also the forming substrate of the local soil. The soil in the experimental site is Dystric Cambisol (IUSS Working Group WRB, 2015), with three mineral horizons $(\mathrm{Au}, 0-5.0 \mathrm{~cm}$, Bv horizon $5-110 \mathrm{~cm}$ with gradual transition to $\mathrm{C}$ horizon).

\subsection{Field and laboratory work}

\subsubsection{Dye tracer application}

In April 30, 2012, BB solution with $10 \mathrm{~g} \mathrm{l}^{-1}$ concentration was applied by a sprinkler with $100 \mathrm{~mm} \mathrm{~h}^{-1}$ intensity over a $1 \times 1 \mathrm{~m}$ plot. Prior to the BB application, the litter horizon was removed because of its high interception capacity. After the dye application a series of four vertical profile cuts were excavated at different times after 2 (CUT 2), 24 (CUT 24), 27 (CUT 27), and 504 hours (CUT 504) after the application of the BB solution. The air temperature, precipitation, and potential evapotranspiration at the experimental site monitored by automatic station of the EMS Brno Company, are presented in Fig. 1. As can be seen from the Fig. 1, no rainfall was fell during the period between the $\mathrm{BB}$ application and the excavation of the CUT 2, CUT 24, and CUT 27 profiles, but some rains fell between the CUT 27 and CUT 504 exposition times (Fig. 1). 


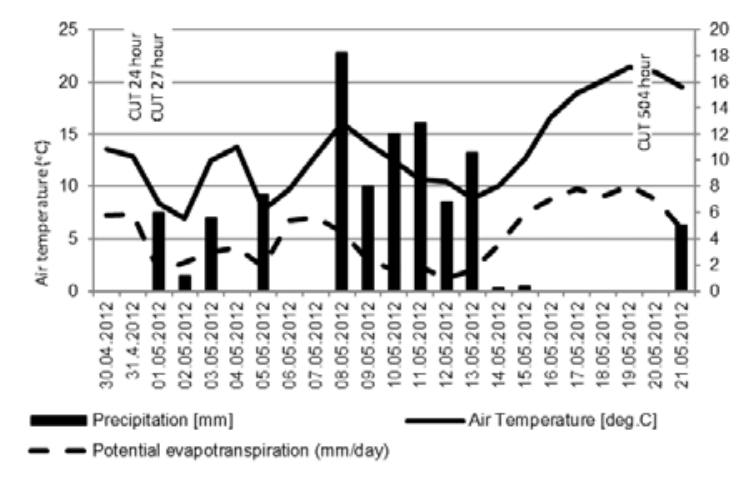

Fig. 1. Temperature, potential evapotranspiration and precipitation at the experimental site.

\subsubsection{Dye coverage determination}

After exposition of particular CUTs, the $1 \times 1 \mathrm{~m}$ grey frame was installed around each soil profile and digital photographs were obtained. After taking digital photographs several procedures were performed to evaluate the spatial concentration of the BB dye (i) Geometric correction; (ii) white-balance and exposure correction; (iii) calibration and (iv) evaluation of the dye concentration. To evaluate dye coverage $(\mathrm{Dc})$ the processing framework in GNU R (R Development Core Team) and C with help of ImageMagick image processing library and with a resolution of $500 \times 1,000$ pixels (i.e., one pixel represents a $1 \times 2 \mathrm{~mm}$ ), were used.

Dye coverage $\left(D_{c}\right)$ calculation is described in Eq. [1] (Flury et al. 1994):

$$
D_{c}=\left(\frac{D_{a}}{D_{a}+N D_{a}}\right) \times 100
$$

where, $D_{a}$ is the surface area in the cut that stained by dye, and $N D_{a}$ is the surface area in the cut that is not stained.

\subsubsection{Sampling procedure}

Three samples from each $10 \mathrm{~cm}$ layer of each CUTs by Kopecky-cylinder with volume of $100 \mathrm{~cm}^{3}$ were taken with consideration of colouring intensity: samples labelled as NC (from sites not affected by BB dye), MC (taken from zones with middle colouring) and IC (samples intensively coloured by BB dye solution). Totalling, 120 soil samples were taken for physical and chemical analysis during 20 days from CUT 2 to CUT 504 soil profiles, but only NC and IC samples (80 samples in total) were taken into the account regarding proposed article. Finishing the sampling at experimental site, the soil samples were taken from the both the right and the left sides of CUTs located approx. $35 \mathrm{~cm}$ apart from $1 \times 1 \mathrm{~m}$ experimental plot, where no BB tracer had been applied on soil surface (referred as REFs).Two samples were taken from each $10 \mathrm{~cm}$ layer, i.e. 20 samples in total from REF zone.

\subsubsection{Soil texture and skeleton content determination}

In order to specify soil skeleton volume in soil samples from both the CUTs and the REF profiles, separation of the skeleton from the fine earth was achieved by dry and wet sieving, additional washing of the rock fragments gave clast with clean surfaces following the procedure proposed by Corti et al. (1998) and Certini et al. (2004). The soil skeleton volume was obtained by water displacement after the clast were completely water saturated (Corti et al. 1998). Soil texture, or size distribution of mineral particles was determined by standardized sedimentation pipette method in water column in sense of Fiala et al. (1999).

\subsubsection{Determination of $\mathrm{Na}^{+}$in soil exchangeable complex}

The concentration of $\mathrm{Na}^{+}$in soil exchangeable complex was determined by its replacing with $0.15 \mathrm{M} \mathrm{NH}_{4} \mathrm{Cl}$ and by AAS analysis of leachate via Avanta AAS, with nitroacetylene burner with automatic rotation.

\subsubsection{Determination of $\mathrm{pH}\left(\mathrm{H}_{2} \mathrm{O}\right)$}

The $\mathrm{pH}\left(\mathrm{H}_{2} \mathrm{O}\right)$ as an indication of the acidity or alkalinity of soil was measured according to Fiala et al. (1999), by $\mathrm{pH}$ meter Hamma HI 221 of soils suspended in a distilled water (from which $\mathrm{CO}_{2}$ was abstracted via $30 \mathrm{~min}$. boiling), under $1: 2.5$ soil : water ratio and mechanical stirring. Laboratory balance Mettler PL 1200 were used for weighing of fine earth $(20.00 \mathrm{~g})$.

\subsubsection{Determination of total content of $\mathrm{Al}, \mathrm{Si}$ and $\mathrm{Fe}$}

Total chemical analyses of soil (called as silicate analysis) of REF soil profiles were determined by inductively coupled plasma atomic emission spectrometry (ICP-AES) by EL spol. s r. o. accredited laboratory. However, before the ICP-AES analyses, the soil samples were crushed and pulverized in agate mill. After that, the specific dissolution was made.

\section{The dissolution of $\mathrm{Na}_{2} \mathrm{O}, \mathrm{K}_{2} \mathrm{O}, \mathrm{LiO}_{2}, \mathrm{P}_{2} \mathrm{O}_{5}$}

The $\mathrm{HF}$ and $\mathrm{HClO}_{4}$ were added into the samples in the Teflon dishes and the samples were evaporated. After cooling, $\mathrm{HF}$ and a the saturated $\mathrm{H}_{3} \mathrm{BO}_{3}$ solution were added. After drying, the samples were dissolved in nitric acid $(1: 1)$ and transferred into the graduated flasks. After evaporation to dryness and next cooling, the samples were dissolved in $\mathrm{HNO}_{3} 1: 1$ and, after cooling, the samples were transferred into the polypropylene graduated flasks. 
The dissolution of $\mathrm{SiO}_{2}, \mathrm{Al}_{2} \mathrm{O}_{3}, \mathrm{Fe}_{2} \mathrm{O}_{3}, \mathrm{TiO}_{2}, \mathrm{MnO}$, $\mathrm{CaO}, \mathrm{MgO}$

$\mathrm{Na}_{2} \mathrm{O}_{2}$ and samples were weighed into the Pt crucibles, where they were thoroughly mixed with plastic rod. The crucibles with the lids were put into the muffle furnace. After removing the crucibles from the furnace, the samples were cooled, transferred into beakers and sprinkled with hot distilled water. After 20 minutes, concentrated $\mathrm{HCl}$ was added into the samples and the samples were leached in the baths. Subsequently, the crucibles, as well as the lids, were rinsed with distilled water and the resulting aliquots were poured into the graduated flasks, to which the internal standard solution, as well as the distilled water were added to the marks, and after that, the samples were mixed.

\section{$S-$ Total}

The samples were weighed into the beakers, where a $1: 3$ mixtures of $\mathrm{HCl}$ and $\mathrm{HNO}_{3}$ were added. The beakers were covered with a glass slides where they cooled to next day. After that, the solutions were heated for 1 hour in sand bath. Subsequently, the glass slides were rinsed with distilled water and the solutions were evaporated to dryness. Concentrated $\mathrm{HCl}$ was added, causing the dissolution of samples under a clock glasses in a sand bath for 30 minutes. After that, the glass slides were rinsed with distilled water, the solutions were cooled, and transferred with distilled water into the graduated flasks. The graduated flask was filled with distilled water to the marks and thoroughly mixed.

\section{$\mathrm{S}-\mathrm{SO}_{3}$}

The samples were weighed into the breakers. $\mathrm{HCl} 1: 1$ was added, the beakers were covered with a glass slide and, upon completion of the reaction, they boiled on a cooker. After cooling, the slides were rinsed and the samples were poured into graduated flasks filled with distilled water and thoroughly mixed.

\section{$S$ sulphidic: $S$ total $-\mathrm{SO}_{3}$}

The XRF spectrometry for analysis of $\mathrm{Al}, \mathrm{Si}$, Fe concentration in fine earth soil samples was applied, as validation characteristics of this analytical method provided by Vojteková et al. (2010) to show its compatibility with the methods used in reference laboratories. We used Thermo Scientific Niton XL3t Series XRF analyzer with GOLDD technology, with low detection limits of light elements (e.g., $\mathrm{Mg}, \mathrm{Al}, \mathrm{Si}, \mathrm{P}$ ). The sensitivity, or limits of detection (LOD) in ppm $\left(\mathrm{mg} \mathrm{kg}^{-1}\right)$ of the Niton XL3t GOLDD technology analyzer, for $\mathrm{SiO}_{2}$ matrix, $\mathrm{SiO}_{2}$ matrix with $10 \%$ iron, and a typical Standard Reference Material (SRM) can be find on thermofisher.com website. During the measurement, the Mining Calibration Mode was used and the MAIN, HIGH, LOW, LIGHT filters with time measurement of $30.0 \mathrm{~s}$. per filter were applied.

The fine earth soil samples were before XRF analyses pulverized and homogenized using the RETSCH Mixer
Mills (MM 301). After that, by SPECAC hydraulic press with a maximum pressure limit of $15.000 \mathrm{~kg}$, the pellets with diameter $(32 \mathrm{~mm})$ were prepared. In total, 80 pellet samples from IC and NC zones of CUT2 - CUT 504 were measured, 20 pellet samples from REF profile, and each sample were measured twice, to ensure representativeness of acquired chemical analyses.

\subsubsection{The stocks of elements}

Because we knew the bulk density and volume of the soil (as the soil samples were taken by Kopecky cylinder of $100 \mathrm{~cm}^{-3}$ ), i.e., fine earth + soil pores, without coarse fragments with diameter $>2 \mathrm{~mm}$, the concentration of chemical elements, or $\mathrm{Na}^{+}$concentration in soil exchangeable complex (CC) stock (CCS) was computed by assuming the CCS in all ten $0.1 \mathrm{~m}$ layers of all four soil profiles (CUTs) derived from both the IC and the NC zones surrounding the PF pathways as well as separately for the REF CUTs not affected by BB dye, at each sampling point according to:

$$
C C S=B D \times C C \times d \times(1-c f)
$$

where $C C S, B D, C C, d$ and $c f$ are, element stock $\left(\mathrm{kg} \mathrm{m}^{-2}\right)$, bulk density $\left(\mathrm{kg} \mathrm{m}^{-3}\right)$, element stock $\left(\mathrm{kg} \mathrm{kg}^{-1}\right)$, soil layer thickness $(0.1 \mathrm{~m})$ and volumetric fraction of soil skeleton $\left(\mathrm{m}^{3} \mathrm{~m}^{-3}\right)$, respectively.

\section{Results}

\subsection{Verification of working hypothesis}

The study of soil texture differences among the particular CUTs and the REF zone according to USDA soil taxonomy detected minimal differences regarding soil texture (Fig. 2) and volumetric skeleton contents (Fig. 3). The homogeneity of soil pedon under investigation was confirmed by both the electric resistivity and the GPR measurements (Bebej et al. 2013) to suggest, the minimal spatial variances in soil pedon exist. From mineralogical point of view, the soil skeleton is monotonous and consist of clasts of extremely acid quartzite, sandstones and mica slates.

The mica slates are represented by grey-green one's, and red coloured varieties, but its chemical composition, as compared with the fine earth soil samples (Table 1), is relatively similar. Generally, the silicate analyses of fine earth soil samples to show no differences in chemical and mineralogical composition of soil in upside of REF profile $(0-60 \mathrm{~cm})$, therefore regarding the skeleton composition, its volumetric content and soil textures in the CUTs soil profiles we can propose the chemical composition is similar that determined in REF profile, and working hypothesis proposed about spatial homogeneity of soil pedon is true. 


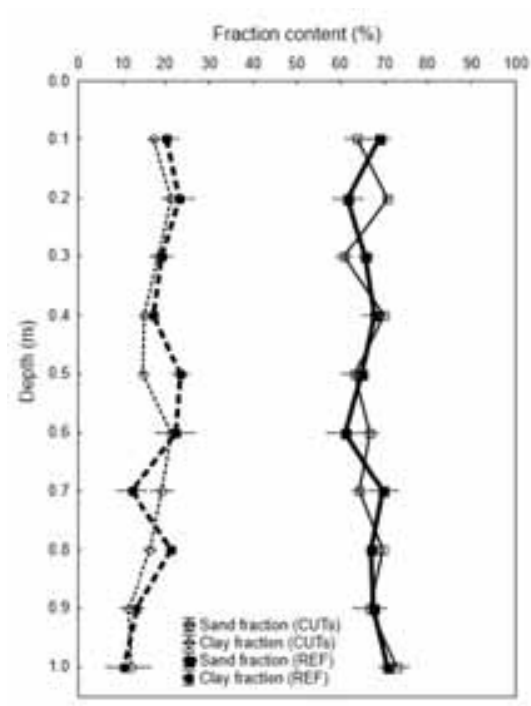

Fig. 2. Particle size distribution of sand and clay fractions within the CUTs and REF zone profiles.

\subsection{Characterisation of dye pattern profiles}

Typical infiltration patterns observed in particular CUTs, as well as their dye coverages (Dc) are documented in Fig. 3. In all soil profiles macropore dye pathway structures are well visible, but some differences among them also manifested. Within the CUT 2, macropore pathways are narrow and the top of CUT 2 profile is only slightly covered by BB dye. On the contrary, within the CUT 24 the top layer of soil profile is heavily covered by BB dye and in both the CUT 24 and CUT 27 profiles the macropore pathways are broad what indicate the growth in macropore-soil matrix interaction. The macropore pathways in CUT 504 is different the rest CUTs and finger-like structures are evident.

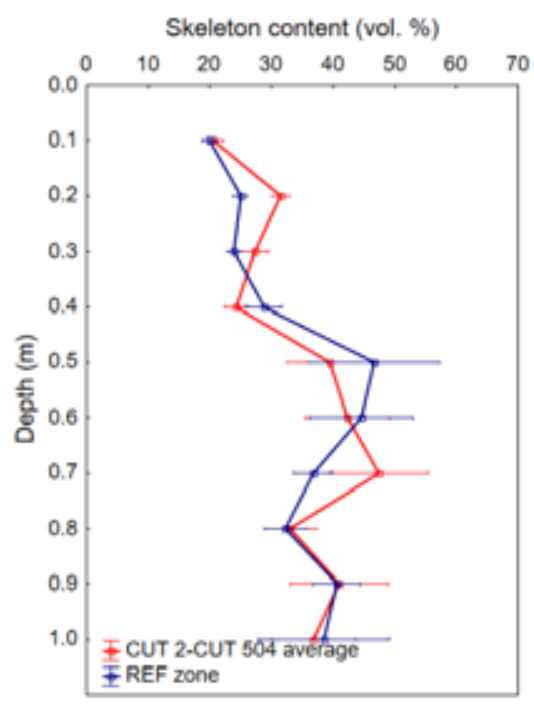

Fig. 3. Volumetric skeleton contents in soil samples withdrawal from both the experimental plots (CUT 2 - CUT 504) and the REF zone.

\section{3. $\mathrm{pH}\left(\mathrm{H}_{2} \mathrm{O}\right)$ values}

The distribution of $\mathrm{pH}\left(\mathrm{H}_{2} \mathrm{O}\right)$ values in both the experimental plot (CUT 2-CUT 504) and the REF soil profile are presented in Fig. 4. It can be seen from Fig. 4, that irrigation with $\mathrm{BB}$ dye solution $(\mathrm{pH}=7)$ abruptly increased the $\mathrm{pH}\left(\mathrm{H}_{2} \mathrm{O}\right)$ values recorded in soil profiles of experimental plot, and that these changes are visible in all soil samples from both the IC and the $\mathrm{NC}$ zones. The second important feature is zonal character of $\mathrm{pH}\left(\mathrm{H}_{2} \mathrm{O}\right)$ curves regarding the $\mathrm{REF}$ zone, while this trend abruptly changes about $60 \mathrm{~cm}$ depth (Fig. 4): in the top part of the soil profiles the drop in $\mathrm{pH}\left(\mathrm{H}_{2} \mathrm{O}\right)$ is observed from CUT 2 and CUT 24 to CUT 505 profiles, while below $60 \mathrm{~cm}$ this trend is opposite.

Surprisingly, the $\mathrm{pH}\left(\mathrm{H}_{2} \mathrm{O}\right)$ changes observed in both the IC and the $\mathrm{NC}$ zones manifest, in general, in similar intensity, hence colouring intensity of soil samples is not the indication of $\mathrm{pH}$ changes.

Table 1. The silicate analyses of fine earth soil samples from soil profile of REF zone as compared with chemical composition of grey-green slates (GGS), and red-coloured slates (RS) of soil skeleton.

\begin{tabular}{|c|c|c|c|c|c|c|c|c|}
\hline & REF $10 \mathrm{~cm}$ & REF $20 \mathrm{~cm}$ & REF $30 \mathrm{~cm}$ & REF 40 cm & REF $50 \mathrm{~cm}$ & REF $60 \mathrm{~cm}$ & REF 40 cm (GGS) & REF 40 cm (RS) \\
\hline$\overline{\mathrm{SiO}_{2}}$ & 68.96 & 68.05 & 68.76 & 68.94 & 70.04 & 68.81 & 74.81 & 70.04 \\
\hline $\mathrm{Al}_{2} \mathrm{O}_{3}$ & 14.75 & 14.91 & 14.68 & 14.83 & 14.13 & 14.86 & 14.02 & 14.13 \\
\hline $\mathrm{Fe}_{2}^{2} \mathrm{O}_{3}^{3}$ & 4.28 & 4.41 & 4.33 & 4.41 & 4.21 & 4.36 & 1.93 & 4.21 \\
\hline $\mathrm{FeO}$ & 0.6 & 0.74 & 0.4 & 0.3 & 0.41 & 0.14 & 0.2 & 0.41 \\
\hline $\mathrm{TiO}_{2}$ & 0.612 & 0.636 & 0.613 & 0.631 & 0.613 & 0.629 & 0.188 & 0.613 \\
\hline $\mathrm{MnO}$ & 0.033 & 0.027 & 0.042 & 0.026 & 0.025 & 0.024 & 0.039 & 0.025 \\
\hline $\mathrm{CaO}$ & 0.03 & 0.04 & 0.12 & 0.06 & 0.05 & 0.06 & $<0.01$ & 0.05 \\
\hline $\mathrm{MgO}$ & 1.38 & 1.4 & 1.4 & 1.4 & 1.36 & 1.48 & 1.27 & 1.36 \\
\hline $\mathrm{Na}_{2} \mathrm{O}$ & 0.49 & 0.46 & 0.48 & 0.46 & 0.46 & 0.44 & 0.69 & 0.46 \\
\hline $\mathrm{K}_{0}^{2} \mathrm{O}$ & 4.07 & 4.04 & 4.13 & 4.08 & 3.85 & 4.17 & 4.23 & 3.85 \\
\hline $\mathrm{LiO}_{2}$ & 0.009 & 0.01 & 0.009 & 0.01 & 0.009 & 0.009 & 0.005 & 0.009 \\
\hline $\mathrm{P}_{2} \mathrm{O}_{5}$ & 0.08 & 0.12 & 0.08 & 0.08 & 0.08 & 0.09 & 0.07 & 0.08 \\
\hline$S^{2}$ total & 0.01 & 0.01 & 0.02 & 0.02 & 0.01 & 0.01 & $<0.01$ & 0.01 \\
\hline S sulfidic & $<0.01$ & $<0.01$ & $<0.01$ & $<0.01$ & $<0.01$ & $<0.01$ & $<0.01$ & 0.01 \\
\hline Loss of ignition & 4.94 & 5.01 & 4.78 & 4.56 & 4.66 & 4.46 & 2.83 & 4.66 \\
\hline Loss of drying & 0.66 & 0.68 & 0.62 & 0.64 & 0.55 & 0.84 & 0.27 & 0.55 \\
\hline Total & 100.9 & 100.5 & 100.5 & 100.4 & 100.5 & 100.4 & 100.6 & 100.5 \\
\hline
\end{tabular}




\section{4. $\mathrm{Na}^{+}$concentration in soil exchangeable complex}

The sodium represents $5,8 \%$ of BB FCF dye molecule weight component; therefore, the sodium represents important part of dye solution to be applied into the soil during irrigation experiment.

The analyses of $\mathrm{Na}^{+}$in dye pattern profiles compared to REF revealed, that in CUT 2 there are biggest differences in $\mathrm{Na}^{+}$concentration between IC zones and REF (Fig. 5), and that in the top part of the soil profile $(0-$ $60 \mathrm{~cm}$ ) the gradual drop in $\mathrm{Na}^{+}$concentration i from CUT 2 to CUT 505 profiles s observed in such a way as in case of $\mathrm{pH}\left(\mathrm{H}_{2} \mathrm{O}\right)$ (Fig. 4).
In case of soil samples extracting from $\mathrm{NC}$ zones of macropore $\mathrm{PF}$ pathflows the differences in $\mathrm{Na}^{+}$concentration between particular CUTs and REF are marginal, especially in bottom part of soil profiles (Fig. 4 b). The discrepancies between $\mathrm{pH}\left(\mathrm{H}_{2} \mathrm{O}\right)$ values and $\mathrm{Na}^{+}$concentration in both the IC and NC soil samples can be accounted by increasing of exchangeable sodium in soil exchangeable complex as compared of different soilwater ratio existing in IC and $\mathrm{NC}$ zones of macropore pathflow (Abrol et al. 1988). In sodic soil, the different $\mathrm{Na}^{+}$concentration in soil exchangeable complex existing at different soil : water ratios in IC and $\mathrm{NC}$ zones can produce identical $\mathrm{pH}\left(\mathrm{H}_{2} \mathrm{O}\right)$ values.
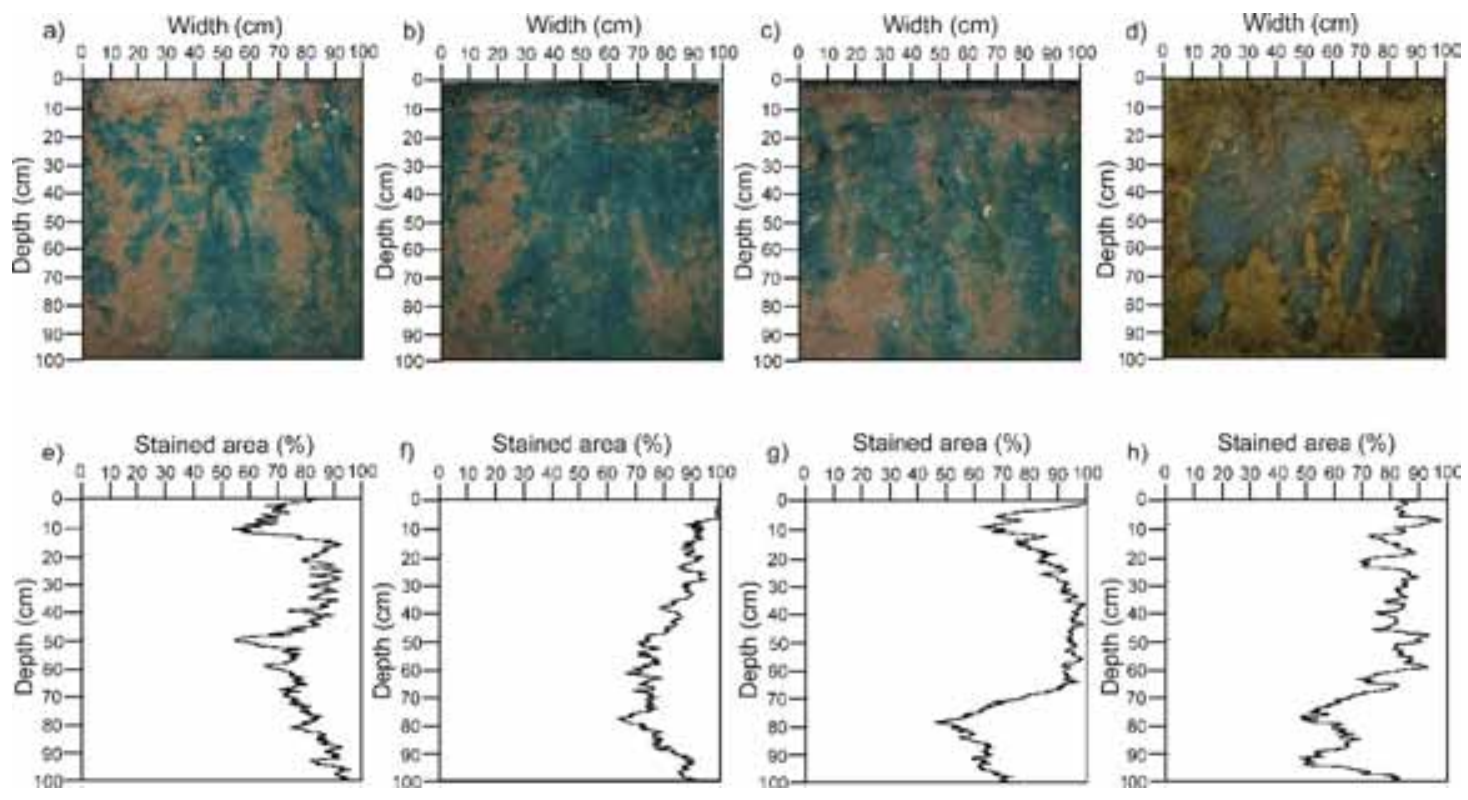

Fig. 4. Infiltration patterns and dye pattern coverages (bottom) within the CUT 2 (a), CUT 24 (b), CUT 27 (c) and CUT 504 (d).
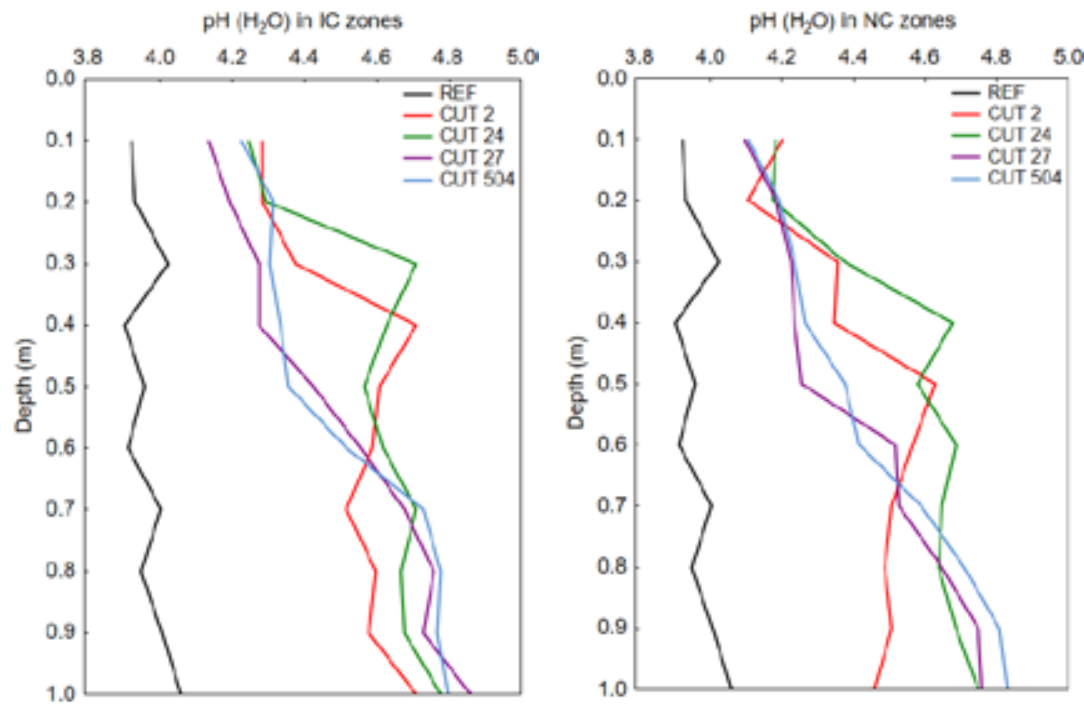

Fig. 5. The $\mathrm{pH}\left(\mathrm{H}_{2} \mathrm{O}\right)$ changes in IC and NC zones of macropore PF pathflows of CUT 2 to CUT 504 soil profiles regarding the $\mathrm{pH}\left(\mathrm{H}_{2} \mathrm{O}\right)$ in soil profile of REF zone. 
According to Abrol et al. (1988) difference about $1 \mathrm{pH}$ unit indicates that the soil contains more than 15 percent exchangeable sodium. The principal cause of alkaline reaction of sodic soils is the hydrolysis of the exchangeable sodium by $\mathrm{H}_{2} \mathrm{O}$ which results in an increase in the $\mathrm{OH}^{-}$ion concentration and increased soil $\mathrm{pH}$. Ions such as $\mathrm{Na}^{+}$are unable to compete as strongly as the more tightly held ions such as $\mathrm{Ca}^{2+}$ and $\mathrm{Mg}^{2+}$, so exchangeable $\mathrm{Na}^{+}$is hydrolysed to a much greater extent and produce a higher $\mathrm{pH}$ than do exchangeable $\mathrm{Ca}^{2+}$ or $\mathrm{Mg}^{2+}$ (Abrol et al. 1988).

a)

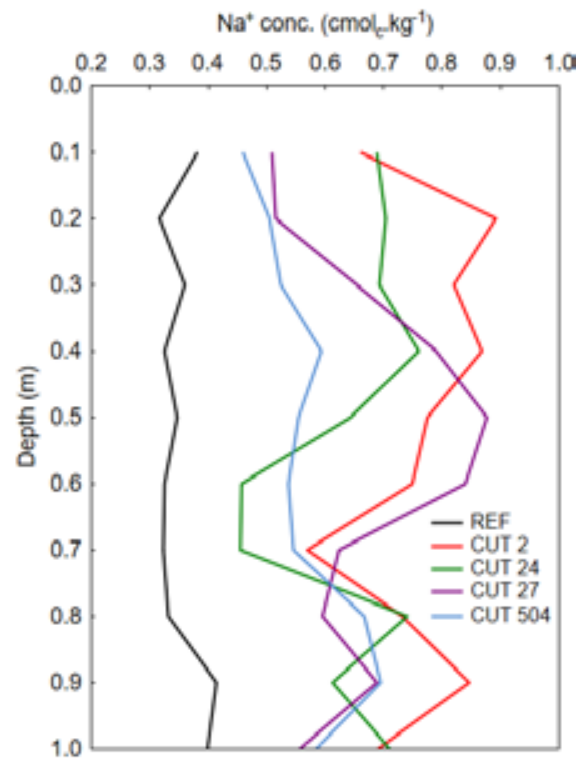

\subsection{Al, Si and Fe concentration in fine earth soil samples}

The XRF analyses of Al, Si and Fe of fine earth soil samples extracted from IC zones of macropore PF path flows of CUT 2 - CUT 405 soil profiles (Fig. 7) in general to show great concentration changes regarding REF soil profiles and this changes reaches its maximum within the CUT 2 profile. In this case for all analysed elements marked depletion in concentration - regarding to REF - is observed. On the other hand, in the case of CUT 27 and CUT504 soil profiles, the concentration of Al, Si and $\mathrm{Fe}$ is close to concentration measured in REF soil profile.

b)

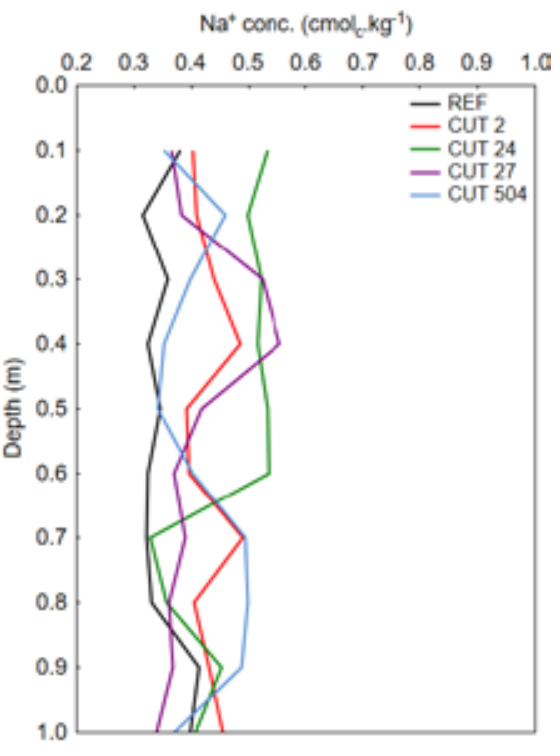

Fig. 6. The concentration changes of $\mathrm{Na}^{+}\left(\mathrm{cmol} \mathrm{kg}^{-1}\right)$ in soil exchangeable complex extracting from IC (a) and NC (b) zones of macropore PF pathflows of CUT 2 - CUT 504 dye pattern profiles regarding the REF soil profile.

a)

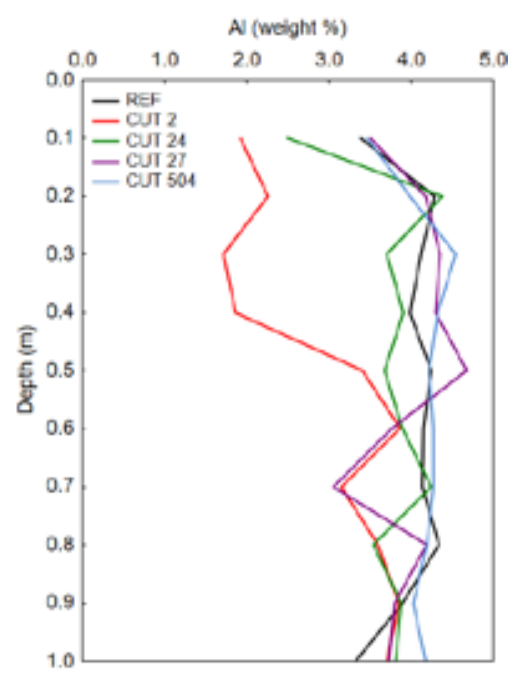

b)

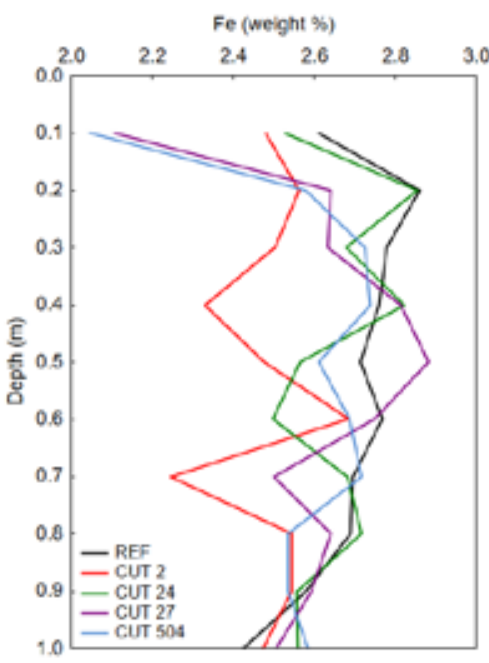

c)

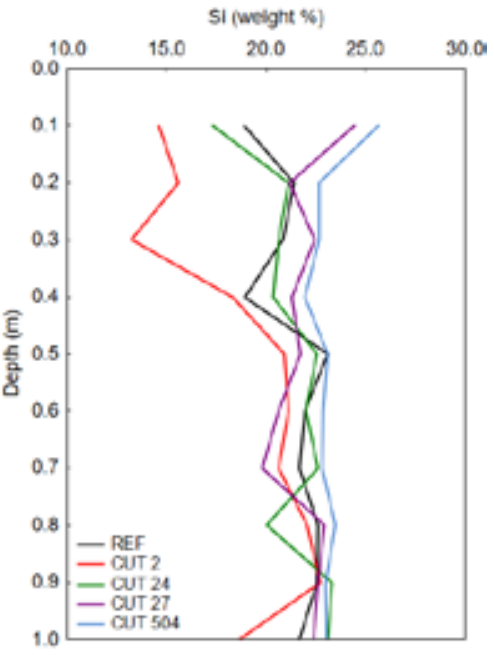

Fig. 7. The concentration changes (weight \%) of $\mathrm{Al}(\mathrm{a}), \mathrm{Fe}(\mathrm{b})$ and $\mathrm{Si}(\mathrm{c})$ in fine earth soil samples extracted from IC zones of macropore PF path flows of CUT 2 - CUT 405 soil profiles determined by XRF analyses regarding the REF zone soil profile. 


\section{Discussion}

The mobility and transport of $\mathrm{Al}, \mathrm{Fe}, \mathrm{Si}$ and organic matter in soils at present is especially related with the podzolization process issue. According to Bloomfield (1954) dissolved organic matter play an important role in the translocation of $\mathrm{Al}$ and $\mathrm{Fe}$ in podzols. By fulvate theory (e.g. Petersen 1976) the fulvate acids dissolves primary and secondary minerals as well as the amorphous materials in the E horizon to form dissolved organic $\mathrm{Al} / \mathrm{Fe} \mathrm{com-}$ plexes. By “anorganic” podzolization theory (Anderson et al. 1982; Farmer \& Lumsdon 2001) inorganic Al, Si and $\mathrm{Fe}$ are translocated via (proto)imogolite sols from the eluvial to the illuvial horizons, where its precipitation in the form of immogolite, causes the development of $\mathrm{Bh}$ and Bs horizons. Gustafsson et al. (2001) propose immobilization of $\mathrm{Al}$ in $\mathrm{B}$ horizons in the form of inorganic precipitates at the higher $\mathrm{pH}$ values $(>4.2)$, however, they suggest that precipitation is induced by the equilibrium of dissolved $\mathrm{Al}$ with $\mathrm{Al}(\mathrm{OH})_{3}$ (s). Lundström et al. (2000), in contrast with the classical fulvate theory propose that complexation of $\mathrm{Al}$ and $\mathrm{Fe}$ to low-molecular weight (LMW) organic acids plays a main role in the mobilization of $\mathrm{Al}, \mathrm{Fe}$ and organic matter from podzol $\mathrm{E}$ horizons and microbial degradation of the LMW organic in the soil causes precipitation of inorganic $\mathrm{Al}$ and $\mathrm{Fe}$ complexes. Mossin et al. (2002), Van Breemen \& Buurman (2002) supposed that different mechanisms of podzolization taken place in different locations, regarding the composition of parent materials and climate conditions.

Total aluminum is measured in soils because it provides useful information on the characterization of soils with respect to the origin of parent materials and weathering (Mulder et al. 1989), however, much higher attention is addressed to exchangeable and extractable aluminium study, due to formulation of lime requirements for acid soils (Kamprath 1970, 1980; Juo \& Kamprath 1979; Oates \& Kamprath 1983) and because of its importance as a predominant cation in acid soils, where the exchangeable aluminum is a critical variable in establishing effective cation exchange capacity (ECEC) values. (Mulder et al. 1987; Rasmussen et al. 1991).

Once soil pH is lowered much below 5.5, aluminosilicate clays and aluminum hydroxide minerals begin to dissolve, releasing aluminum-hydroxy cations and $\mathrm{Al}\left(\mathrm{H}_{2} \mathrm{O}\right)_{6}{ }^{3+}$ that then exchange with other cations of soil colloids. The fraction of exchange sites occupied by $\mathrm{Al}\left(\mathrm{H}_{2} \mathrm{O}\right)_{6}{ }^{3+}$ and its hydrolysis products can become large once the soil $\mathrm{pH}$ falls below 5.0. Furthermore, as the $\mathrm{pH}$ is lowered, the concentration of soluble aluminum, which is toxic, increases.

Generally, the mobilization of aluminium may be due to: dissolution of Al-compounds via acidification process, ion-exchange of $\mathrm{Al}$-ions with cations as $\mathrm{H}^{+}, \mathrm{Ca}^{2+}$, $\mathrm{Mg}^{2+}, \mathrm{NH}_{4}^{+}$, and finally, by complexation with organic substances, like humic and fulvic acids (Kotowski et al. 1994). Kotowski et al. (1994) studied the mobilization of aluminium in laboratory experiments using podzol soils and mineral acids $\left(\mathrm{H}_{2} \mathrm{SO}_{4}, \mathrm{HNO}_{3}\right)$ and fertilizer salts i.e. $\left(\mathrm{NH}_{4}\right)_{2} \mathrm{SO}_{4}$ and $\left.\mathrm{HN}_{4} \mathrm{NO}_{3}\right)$. They found, that mobilization of aluminium by $\mathrm{HNO}_{3}$ was in most cases higher that by $\mathrm{H}_{2} \mathrm{SO}_{4}$ for the same concentrations, while for fertilizer salt solutions the mobilization of aluminium was between that observed for $\mathrm{H}_{2} \mathrm{SO}_{4}$ and $\mathrm{HNO}_{3}$. These results to demonstrate the sodium as essential constituent of BB dye (sodium salt) may mobilize the aluminium from soil exchangeable soil complex of acidic soils, via soil-exchangeable processes.

In acid soils, $\mathrm{Al}^{3+}$ and the associated hydrolysis products $\mathrm{AlOH}^{2+}$, and $\mathrm{Al}(\mathrm{OH})^{+}$dominate exchange phase charge followed by $\mathrm{Ca}, \mathrm{Mg}^{2+}, \mathrm{Na}^{+}$and $\mathrm{K}^{+}$(Essington 2015). However, high concentration of one cation will displace an adsorbed cation from the exchanger even if adsorbed cation is higher on the lyotropic series by Mass Action Law. High concentration of sodium in the initial BB solution may indicate situation the mass action law can come in force and $\mathrm{Na}^{+}$will displace an adsorbed cation from the exchanger even if the adsorbed cation is higher on the lyotropic series - e.g., $\mathrm{Al}^{3}$ (Plaster 2014).

The irrigation experiment with $\mathrm{BB}$ dye solution on experimental plot caused dramatic changes in $\mathrm{pH}\left(\mathrm{H}_{2} \mathrm{O}\right)$ characteristics of soil samples from CUT 2 - to CUT 504 (Fig. 1). The abrupt increase of $\mathrm{pH}$ observed in CUT 2 and CUT 24 profiles to show, the dissolved $\mathrm{Na}^{+}$ions of dye solution caused increase of exchangeable sodium in acid soil exchangeable complex and $\mathrm{Al}^{3+}$ and its hydrolysis products were partly displaced and mobilised. The Fig. $4 \mathrm{a}$ and Fig. $5 \mathrm{~b}$ to illustrate the antagonistic behaviour of $\mathrm{Na}^{+}$as constituent of soil exchangeable complex and the aluminium in fine earth soil samples of IC zones within the CUT 2 profile what indicate the ion-exchange reaction can partially explain the chemical changes observable in $\mathrm{Al}$ concentration in CUT 2 profile. However, the overall $\mathrm{Al}, \mathrm{Si}$ and $\mathrm{Fe}$ chemical changes recorded within the CUT 2 profile regarding the REF soil profile to suggest the another processes governs the observable mass depletion of fine earth soil samples within this profile and that is way the observed $\mathrm{Al}(\%)$ vs. $\mathrm{Na}^{+}\left(\mathrm{cmol}_{\mathrm{c}} \mathrm{kg}^{-1}\right)$ negative correlation is statistically non-significant $(p=$ 0.082) for IC zones.

Existing breaking point in concentration of $\mathrm{Al}, \mathrm{Si}$ and Fe observed between the CUT 2 and the rest CUTs was changed by slow gradation changes in the case of rest CUTs, and generally, the mass depletion of $\mathrm{Al}, \mathrm{Si}$ and $\mathrm{Fe}$ in top part of CUT 2 soil profile suddenly turned into the enrichment at the same part of the CUT 27 - CUT 505 profiles (Fig. 6). All this means the time factor play key role and that the reasons of dye solution transport inversion should be understand and explained.

The basic characteristics of two factorial ANOVA for concentration of $\mathrm{Al}, \mathrm{Fe}$ and $\mathrm{Si}$ in fine earth soil, as well as for concentration of $\mathrm{Na}^{+}$in soil exchangeable complex in soil samples from CUT 2 to CUT 504 soil profiles are presented in Table 2. As can be seen, depth, time as well as their concurrence is statistically very significant for $\mathrm{Al}$, $\mathrm{Fe}$ and $\mathrm{Si}$, besides the $\mathrm{Na}^{+}$, where statistical dependence 
was supported only by one factorial ANOVA. It follows from these data, that the $\mathrm{Na}^{+}$concentration is very significantly influenced by colouring intensity $(p=0.000)$ and time $(p=0.001)$, while for $\mathrm{Al}, \mathrm{Fe}$ and Si the colouring intensity (IC and NC zones) is non-significant factor from statistical point of view.

Different behaviour of $\mathrm{Na}^{+}$on one hand, and $\mathrm{Al}, \mathrm{Fe}$ and Si regarding to IC and NC zones on other hand, is key in order to understand the specific behaviour of sodium: 1). sodium is essential part of BB dye solution and regarding to other elements present in soils, his concentration is non-stoichiometric, and is controlled by both the dye-solution transport is soil and the Brilliant Blue concentration in dye solution,

2). sodium as part of dye solution is transported in soil according the processes of adsorption isotherm, where the partitioning of a solute between the aqueous solution and the sorbed phase take place (Kasteel et al. 2002).

$3)$. on the interfaces between the dye solution and surrounding soil also the ion exchange processes take place, principally different of sorption processes which take place on free surface sites, while the ion exchange is controlled by the ionic composition of

$\mathrm{Na}^{+}$concentration changes in soil exchangeable complex
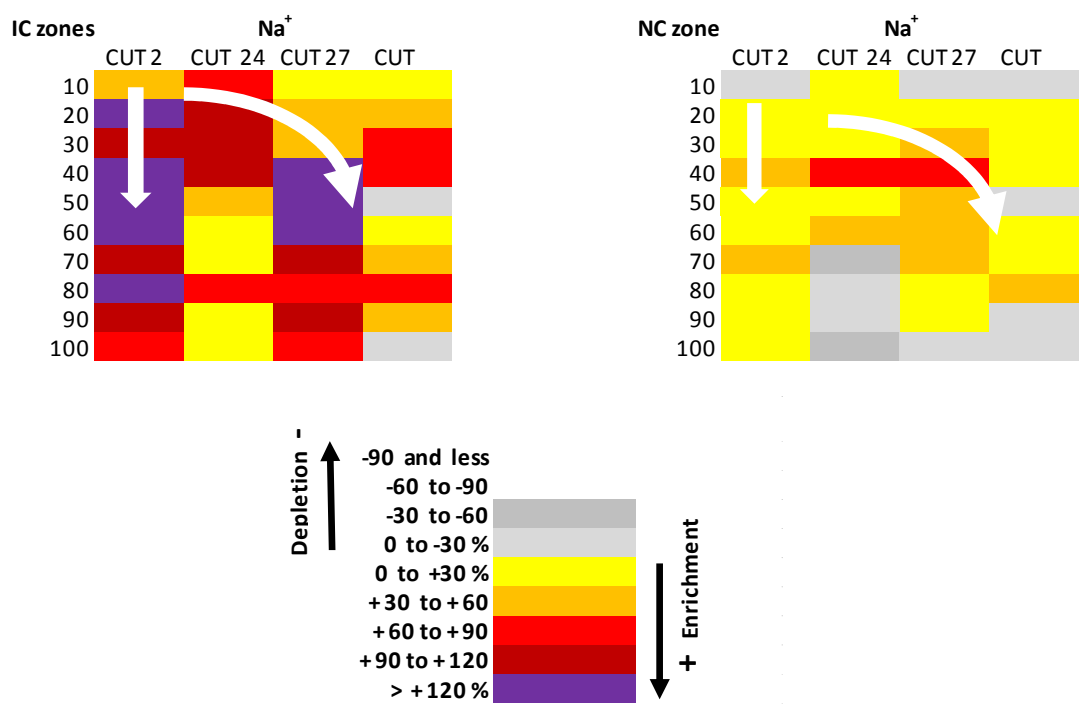

Corresponded Al, Si and Fe concentration changes detected by XRF analyses in IC and NC zones
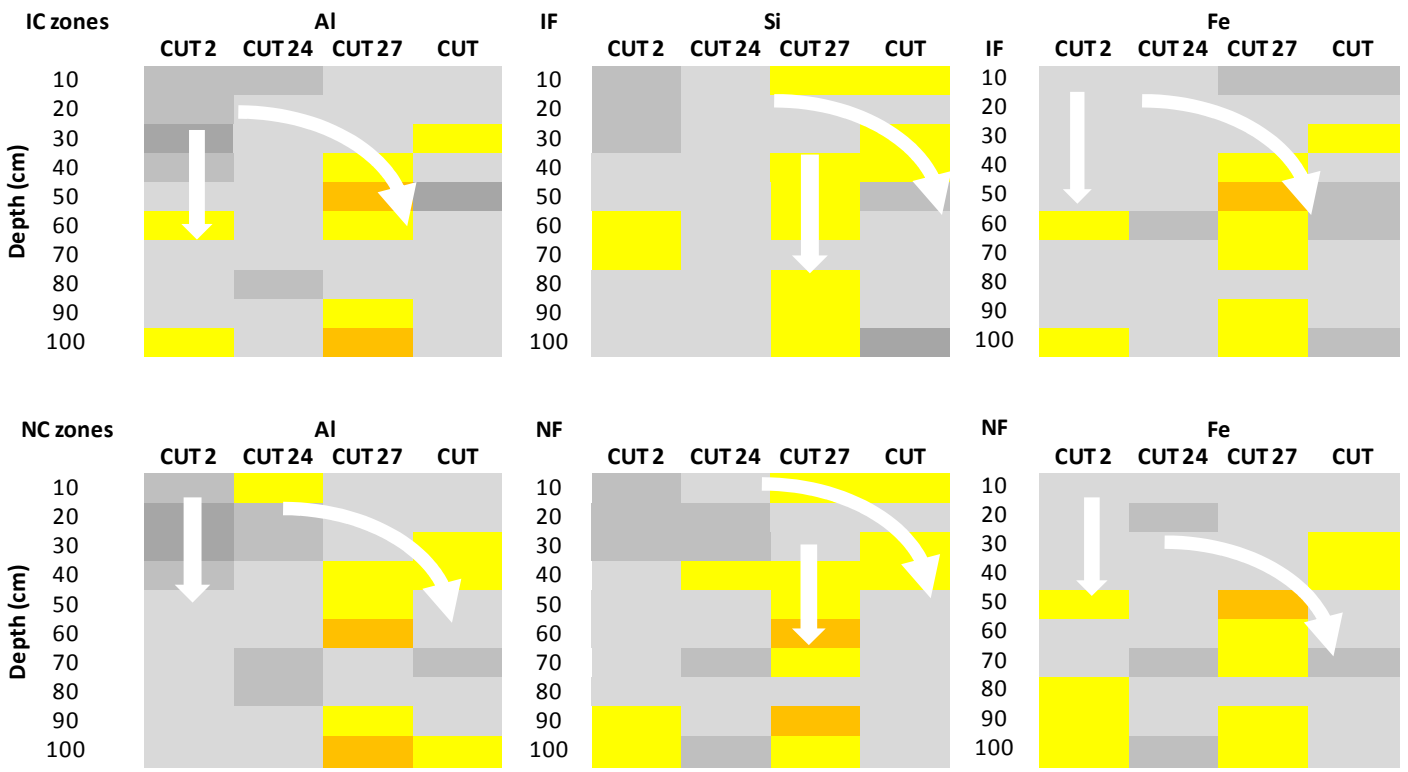

Fig. 8. The concentration changes (\%) of $\mathrm{Na}^{+}$in soil exchangeable complex (a), and corresponded $\mathrm{Al}, \mathrm{Si}$ and Fe concentration changes in coexisted fine earth soil samples extracted from both the IC and NC zones of macropore PF pathflows of CUT 2 CUT 405 soil profiles (b). 
the liquid phase (Nagy \& Kónya 2009). In the case of common action of sorption and ion exchange processes, the spatial separation of sodium and the cations displaced of soil exchangeable complex to be the consequence, and coloured, sodium rich IC zones will not spatially coincide with zones, where the displaced cations to be accumulated,

4). the chemical changes observed in the CUT dye pattern profiles to show the younger processes to be superimposed to older ones', or depletion in concentration of chemical elements suddenly change to enrichment. The effect of such a processes, in consequences, destroy former $\mathrm{NC}$ and IC zones, and the statistical dependencies between the sodium (coloured IC zones) and other chemical components activated by dye solution: soil interaction will reduce.

Table 2. Two factorial analyses of variance of $\mathrm{Al}, \mathrm{S}, \mathrm{Fe}$ and $\mathrm{Na}$ concentration according to depth and time and its interactions.

\begin{tabular}{|c|c|c|c|c|c|c|}
\hline \multirow{3}{*}{ Parameter } & \multicolumn{6}{|c|}{ Tested factor } \\
\hline & \multicolumn{2}{|c|}{ Depth $[\mathrm{cm}]$} & \multicolumn{2}{|c|}{ Time $[\mathrm{h}]$} & \multicolumn{2}{|c|}{ Depth $[\mathrm{cm}]$ * Time $[\mathrm{h}$} \\
\hline & F-ratio & $\mathrm{p}$ & F-ratio & $\mathrm{p}$ & F-ratio & p \\
\hline Al conc. & 19.58 & 0.000 & 220.26 & 0.000 & 12.62 & 0.000 \\
\hline Fe conc. & 13.10 & 0.000 & 12.90 & 0.000 & 7.05 & 0.000 \\
\hline Si conc. & 17.20 & 0.000 & 86.68 & 0.000 & 7.40 & 0.000 \\
\hline $\mathrm{Na}^{+}$conc. & 0.63 & 0.771 & 2.58 & 0.059 & 0.71 & 0.845 \\
\hline
\end{tabular}

The interesting fact to imply from documented analytical data regarding the statement of Allaire et al. (2009) suggested, the standardization of tracer application methods is needed in order the results between different studies to be comparable. For an example, the time of vertical soil profile exposition usually vary from 12 hours (Kasteel et al. 2002) to 1 day (24-hour) after finishing the infiltration experiment (Flurry \& Flühler 1994; Flurry et al. 1994; Hagedorn \& Bundt 2002; Bogner et al. 2012; Bundt et al. 2001; Garrido et al. 2014), or the samples from several vertical profiles exposed on one experimental plot are interpreted without consideration of time factor role (Bundt et al. 2001; Alaoui \& Goetz 2008). The same statement concerns the concentration of applied BB dye tracers, from $3 \mathrm{~g} \mathrm{l}^{-1}$ (Bundt et al. 2001), $4 \mathrm{gl}^{-1}$ (Flurry et al. 1994; Alanoui \& Goetz 2008) to $10 \mathrm{~g} \mathrm{l}^{-1}$ (Kasteel et al. (2002). Different concentration of $\mathrm{BB}$ dye tracers means that different concentration of $\mathrm{Na}^{+}$in dye solution, and different interaction effects of dye solution with surrounding soil will lead to different chemical footprints observed in exposed soil profiles.

The cause of the time-controlled breaking point in observed chemical changes seems to be the spatial-temporal controlled mechanism of dye solution transfer in soil. While classical theory supposes the PF zone to be temporal and spatially stabile within the soil (Ritsema \& Dekker 2000; Hagedorn \& Bundt 2002; Bogner et al. 2012), we suppose dye solution movement via PF to be limited to brief period (CUT 2 profile), as long as are fulfilled the physical preconditions of non-equilibrium flow (Jarvis \& Dubus 2006). After that, at moment when all pores at the soil surface are filled with water, and lateral movement of dye solution from macropore to surrounding soil matrix prevailed, the macropore flow will terminate (Jarvis \& Dubus 2006) and homogenous flows of dye solution became dominant (CUT 24 - CUT 504 profiles).

\section{Conclusion}

The results of small-scale irrigation field experiments to show heavy chemical changes be caused in soil via interaction of $\mathrm{BB}$ dye solution with surrounding soils. Observed spatial-temporal changes in $\mathrm{pH}\left(\mathrm{H}_{2} \mathrm{O}\right)$, chemical composition of fine earth soil, as well as in concentration of $\mathrm{Na}^{+}$in soil exchangeable complex suggested, the BB dye solution didn't represent an inert tracer, but its compounds are involved in mass reaction with surrounding soils. Recorded chemical trends seems to be also the result of competitive processes between the $\mathrm{Na}^{+}$of $\mathrm{BB}$ dye solution (representing Na-salt) and composition of surrounding soil exchangeable complex, and observed distribution of chemical components around the zones of preferred flows stained by BB dye may cause the risk of fatal misinterpretations in line with the statement of both the Flury \& Flühler (1994) and Flury \& Wai (2003).

The observed breaking point in concentration of $\mathrm{Al}$, Si and Fe we preliminary links with breaking point of dye solution movement, when macropore preferred flow changed to equilibrium one. In order to support proposed scenario, detail analyse of dye pattern profiles and its morphometric parameters is needed.

\section{Acknowledgments}

This work was supported both by the Slovak Research and Development Agency under the contract No. APVV-15-0425 and by Scientific Grants Agency of the Ministry of Education and the Slovak Academy of Sciences under the contract No. VEGA 1/0783/15.

\section{References}

Abrol, I. P., Yadav, J. S. P., Massoud, F. I., 1988: SaltAffected Soils and their Management. FAO Soils Bulletin 39, Food and Agriculture Organization of the United Nations, Rome, $131 \mathrm{p}$.

Alaoui, A., Goetz, B., 2008: Dye tracer and infiltration experiments to investigate macropore flow. Geoderma, 144:279-286.

Allaire, S.A., Roulier, S., Cessna, A. J., 2009: Quantifying preferential flow in soils: A review of different techniques. Journal of Hydrology, 378:179-204.

Anderson, H. A., Berrow, M. L., Farmer, V. C., Hepburn, A., Russel, J. D., Walker, W. J., 1982: A reassessment of podzol formation processes. Journal of Soil Science, 33:125-136. 
Bebej, J., Homolák, M., Gregor, J., Škvarenina, J., 2013: The geophysical and geochemical interfaces in slope deposits and its implications regarding to spatial distribution of soil types and subtypes (in Slovak). In: Slaninka, I., Jurkovič, L', Ďurža, O. (eds.): Geochémia, Bratislava, Štátny geologický ústav Dionýza Štúra, 1:10-13.

Bloomfield, C., 1954: A study of podzolization. Part V. The mobilization of iron and aluminium by aspen and ash leaves. Journal of Soil Science, 5:50-56.

Bogner, CH., Borken, W., Huwe, B., 2012: Impact of preferential flow on soil chemistry of a podzol. Geoderma, p. 175-176, 37-56.

Bouma, J., Dekker, L. W., 1978: A case study on infiltration into dry clay soil I. Morphological observations. Geoderma, 20:27-40.

Brady, N. C., Weil, R. R., 2007: The Nature and Properties of Soil. Higher Ed USA, 992 p.

Bundt, M., Widmer, F., Pesaro, M., Zeyer, J., Blaser, P., 2001a: Preferential flow path: biological "hot spots" in soils. Soil Biology \& Biochemistry, 33:729-738.

Bundt, M., Jaggi, M., Blaser, P., Siegwolf, R., Hagedorn, F., 2001b: Carbon and nitrogen dynamics in preferential flow paths and matrix of a forest soil. Soil Science Society of America Journal, 65:1529-1538.

Certini, G., Campbell, C. D., Edwards, A. C., 2004: Rock fragments in the soil support different microbial community from the fine earth. Soil Biology \& Biochemistry, 36:119-1128.

Corti, G., Ugolini, F. C., Agnelli, A., 1988: Classing the soil skeleton (greater than two milllimeters): propose approach and procedure. Soil Science Society of America Journal, 62:1620-1629.

Essington, M. E., 2015: Soil and Water Chemistry: An Integrative Approach, Second Edition. CRC Press, $656 \mathrm{p}$.

Farmer, V.C., Lumsdon, D. G., 2001: Interactions of fulvic acid with aluminium and protoimogolite sol: the contribution of E-horizon eluates to podzolization. European Journal of Soil Science, 52:177-188.

Fiala, K. et al., 1999: The partial monitoring system Soil. The obligatory methods, The Physical properties of soil (in Slovak). Bratislava, Výskumný ústav pôdoznalectva a ochrany pôdy, $142 \mathrm{p}$.

Flury, M., Wai, N. N., 2003. Dyes as tracers for vadose zone hydrology. Reviews of Geophysics, 41, Article number 1002.

Flury, M., Flühler, H., 1994: Brilliant Blue FCF as a dye tracer for solute transport studies. A toxicological review. Journal of Environmental Quality, 23:11081112.

Flury, M., Flühler, H., Jury, W. A., Leuenbereger, J., 1994: Susceptibility of Soils to preferential Flow of Water. Water Resources Research, 30:1945-1954.

Flury, M., Flühler, H., 1995: Tracer characteristics of Brilliant Blue FCF. Soil Science Society America Journal, 59:22-27.
Garrido, F., Serrano, S., Barrios, L., Uruñuela, J., Helmhart, M., 2014: Preferential flow and metal distribution in a contaminated alluvial soil from São Domingos mine (Portugal). Geoderma, 213:103-114.

Germán-Heins, J., Flury, M., 2000: Sorption of Brilliant Blue FCF in soils as affected by $\mathrm{pH}$ and ionic strength. Geoderma, 97:87-101.

Gustafsson, J. P., Berggren, D., Simonsson, M., Zysset, M., Mulder, J., 2001: Aluminium solubility mechanisms in moderately acid Bs horizons of podzolized soils. European Journal of Soil Science, 52:655-665.

Hagedorn, F., Bund, M., 2002: The age of preferential flow paths. Geoderma, 208:119-132.

IUSS Working Group WRB, 2015: World Reference Base for Soil Resources 2014, update 2015. International soil classification system for naming soils and creating legends for soil maps. World Soil Resources Reports No. 106. FAO, Rome

Jarvis, N.J., Dubus, I. G.,2006: State-of-the-art review on preferential flow. Report DL\#6 of the FP6EU-funded FOOTPRINT project [www.eu-footprint.org], 60 p.

Juo, A. S. R., Kamprath, E. J., 1979: Copper chloride as an extractant for estimating the potentially reactive aluminum pool in acid soils. Soil Science Society America Journal, 43:35-38.

Kamprath, E. J., 1970: Exchangeable aluminum as a criterion for liming leached mineral soils. Soil Science Society America, Proceedings, 34:252-254.

Kasteel, R., Vogel, H. J., Roth, R., 2002: Effect of nonlinear adsorption on the transport behaviour of Brilliant Blue in a field soil. European Journal of Soil Science, 53:231-240.

Ketelsen, H., Meyer-Windel, S., 1999: Adsorption of Brilliant Blue FCF by soils. Geoderma, 90:131-145.

Kotowski, M., Pawlowski, L., Seip, H. M., Vogt, R. D., 1994: Mobilization of aluminium in soil collums exposed to acids or salt solutions. Ecological Engineering, 3:279-290.

Kung, K-J. S., 1990: Preferential flow in a sandy vadose zone. I. Field observation. Geoderma, 46:51-58.

Lundström, U. S., van Breemen, N., Bain, D. C., van Hees, P. A. W., Giesler, R., Gustafsson, J. P. et al., 2000: Advances in understanding the podzolization process resulting from a multidisciplinary study of three coniferous forest soils in the Nordic Countries. Geoderma, 94:335-353.

Mossin, L., Mortensen, M., Nørnberg, P., 2002: Imogolite related to podzolization processes in Danish podzols. Geoderma, 109:103-116.

Mulder, J., van Grinsven, J. J. M., van Breemen, N., 1987: Impacts of acid atmospheric deposition on woodland soils in The Netherlands: III. Aluminum chemistry. Soil Science Society America Journal, p. 1640-1646.

Nagy, N. M., Kónya, J., 2009: Interfacial chemistry of rocks and soils. CRC Press, Taylor \& Francis Group, $230 \mathrm{p}$. 
Oates, K. M., Kamprath, E. J., 1983: Soil acidity and liming: I. Effect of the extracting solution cation and $\mathrm{pH}$ on the removal of aluminum from acid soils. Soil Science Society America Journal, 47:686-689.

Perillo, C. A., Gupta, S. C., Nater, E. A., Moncrief, J. F., 1998: Flow velocity effects on the retardation of FD \& C Blue No. 1 food dye in soil. Soil Science Society America Journal, 62:39-45.

Petersen, L., 1976: Podzols and podzolization. DSR Forlag, Copenhagen, 293 p.

Plaster, E., 2014: Soil Sciences and Management.Delmar, CENGAGE Learning, 519 p.

Rasmussen, P. E., Schiff, S. L., Nesbitt, H. W., 1991: The determination of exchangeable cations in acid soils: Errors caused by weathering reactions during neutral salt extraction. Canadian Journal of Soil Science, 71:155-163.

Ritsema, C. J., Dekker, L. W., 2000: Preferential flow in water repellent sandy soils: principles and modeling implications. Journal of Hydrology, p. 231-232, 308-319.
Roth, K., 1995: Steady-state flow in an unsaturated, two-dimensional, macroscopically homogeneous, Miller-similar medium. Water Resources Research, 31:2127-2140.

Sparks, D. L., 2003: Environmental Soil Chemistry.Academic Press, $352 \mathrm{p}$.

Van Breemen, N., Buurman, P., 2002: Soil formation, 1. Kluwer Academic Publishers, Dordrecht, 405 p.

Vojteková, V., Majchrák, A., Mackových, D., Blašková, J., 2010:Development of an Analytical Method for Determination of Major Elements by Energy-Dispersive X-Ray Fluorescence. Chemické listy, 104:10471052.

Weiler, M., 2005: An infiltration model based on flow variability in macropores: development, sensitivity analysis and applications. Journal of Hydrology, 310:294-315. 